\title{
Constraints to Tropical Forest Conservation and Successful Monitoring and Assessment of Land Uses Cover and Change: Do the Forest Definition and Administration Really Matter?
}

\author{
Koffi Ayewa Bassan1, Kouami Kokou², Erin 0. Sills ${ }^{3}$ \\ ${ }^{1}$ Ecole Supérieure d'Agronomie, Université de Lomé, Lomé, Togo \\ ${ }^{2}$ Laboratoire de Botanique de la Faculté des Sciences, Université de Lomé, Lomé, Togo \\ ${ }^{3}$ Department of Forestry and Environmental Resources, North Carolina State University, Raleigh, NC, USA \\ Email:koffibassan@yahoo.fr,kokoukouami@hotmail.com,erin_sills@ncsu.edu
}

How to cite this paper: Bassan, K.A., Kokou, K. and. Sills, E.O (2020) Constraints to Tropical Forest Conservation and Successful Monitoring and Assessment of Land Uses Cover and Change: Do the Forest Definition and Administration Really Matter? Natural Resources, 11, 1-19. https://doi.org/10.4236/nr.2020.111001

Received: November 28, 2019

Accepted: January 13, 2020

Published: January 16, 2020

Copyright $\odot 2020$ by author(s) and Scientific Research Publishing Inc. This work is licensed under the Creative Commons Attribution International License (CC BY 4.0).

http://creativecommons.org/licenses/by/4.0/

\begin{abstract}
We examine the constraints to conservation and to successful forestlands' monitoring/assessments in central Togo through GIS spatial analyses and through a critical overview of the current forestry administration's model. The major findings are that the land classification based on few inventory parameters cannot substitute for "what forest is", rather these inventory parameters constitute a mean to sound forest management and conservation when relevantly decided. Also as these parameters measured from satellite imagery are supplemented by continuous fine management data they may consistently contribute to the classification of the vegetation cover. This helps to suggest that solution to forest degradation/deforestation, and monitoring/ assessment requires data refinement through local forest management. Else, the actual forestry administration is local communities and indigenous people's needs biased because it has been negligent of the cultural forestry practices, the major constraints to conservation and the monitoring/assessment of forest lands. As a common pool-resource, the questions relative to forest cannot be addressed at a single environmental concerns level. Interests are multiple and various along the spectrum from the global environment level to the local environmental level that should be accounted for. Thus we recommend a reconsideration of the forestry administration model. What is required are simple policies processes to define forest management plans that promote simultaneously sustainable forest management while accounting for any stakeholder concern, importantly the cultural forestry that addresses specific local communities and indigenous people's forest related interests.
\end{abstract}




\section{Keywords}

Sustainable Forest Management, Cultural Forestry, Forest Definition, Land Classification, Local People

\section{Introduction}

The monitoring and assessment of tropical forest land have been of serious issues for long. The major reason specific to poor countries is the lack of reliable data on the location and the extent of the forest land. The situation is due first to the fact that the forest literature was not provided by the forest professionals, rather the information on forest was quite documented from travelers' books which are unfortunately often biased, exaggerated, or inaccurate as acknowledged by Richards [1] and Longman and Jenik [2] because some authors have been too quick to generalize, and some others have traveled by the rivers and roads where the observed vegetation cover may not represent a real forest ecosystem. Prior to Richards, Chevalier [3] reported that reports from some previous authors encompassed a lot of fantasies. Another reason is as would remark some social scientist authors such as Fairhead and Melissa [4], pioneer scientists in West Africa have systematically applied the assumptions and techniques elaborated during the colonial era to the actual forest conditions. These false assumptions and techniques have blurred our understanding of tropical forest ecosystems functioning. This uncertainty around the forest data has remained unchanged after decades since forest issues had been of concern. According to our investigation, the earliest field works regarding the vegetation cover in Togo as well as in many other countries of the region, are that of Aubreville's from 1936 to 1949 and Hutchinson's in 1936, reported in Lamouroux [5]. Unfortunately, these works are not easily exploitable because of their mapping low resolution. Recently, the confusion on the extent of the forest land areas as well as that of their changes has been exacerbated by the changing in the assessment methodologies and in the forest related definitions. Data, either from a source to another or from the same source but collected at different time periods contradict each other. For instance, in Togo the forest land assessment using the FAO forest classification yielded 384,880 ha [6] [7], while the national classification provided a figure of $1,392,360$ ha [8], about four folds the figure issued from the classification based on the FAO's forest definition. All this seems to confirm the fact that the magnitudes of the tropical forests today, their location, and their various changes remain unknown in most cases [9]. Chazdon et al. [10] after providing historical overviews of forest definitions and concepts linked the inconsistency in the forest land assessment results to the changing in the forest definitions. Previously, Sasaki and Putz [11] recognized that the definition default has led to forest degradation and affirmed that an adequate definition of forest will promote the switch from degradation to responsible forest management, 
which will help mitigate global warming while protecting biodiversity and contributing to sustainable development. Rather this article aims at showing that the discrepancy in the forest assessment results and the inability to conserve tropical forest lands are the consequences of our current forest administration or governance. The deforestation and the forest degradations may be induced by the inadequate choice of the inventory parameters; but the negligence of the cultural forest practices by the current forest administration has more to do with these issues. Specifically, the first part of the article shows that the forest inventory parameters are tools for sound decisions on forest management, thus, must primarily be forest management objective oriented. Defining what forest ecosystem or other types of vegetation covers are, requires additional information notably, the ecosystem species structure and composition, the life history of the site, the mean biomass periodical increment, and so on. Still in this part the article discusses the effects of the inventory parameter thresholds on forest ecosystems. When properly set these inventory parameter thresholds help to reach sound decision regarding both forest management and conservation, but constrain them when poorly defined or decided. In the second part, the article reviews the actual forestry administration and shows that it has been biased of the local people needs because negligent of the cultural forestry practices. Issues such as agricultural land expansion, wood supply (importantly firewood and charcoal), and many other forestry subsistence practices, that are well documented as factors of deforestation and forest degradation, have not been seriously accounted for in our forestry policy definition. We have focused solely on global warming mitigation as the "common interest". As a common-pool resource the interests on forest must be multiple and embedded on one another from the local users group to the global ones.

\section{Materials and Methods}

The study area is the Central region of Togo. Administratively, it is originally divided into five prefectures which are Blitta, the Plain of Mô River, Sotouboua, Tchamba, and Tchaoudjo. The data for the spatial data analyses are obtained from the global forest dataset made available by the University of Maryland. As presented in the technical notes [12] the global dataset is made of $10 \times 10$ degree tiles, consisting of seven files per tile. All files contain unsigned 8-bit values and have a spatial resolution of approximately 30 meters per pixel at the equator. The major layers are the TREE COVEER in the year 2000, defined as canopy closure for all vegetation taller than $5 \mathrm{~m}$ in height. It is encoded as a percentage per output grid cell, in the range of 0 - 100. The second layer is FOREST COVER GAIN from the year 2000 to 2012 which is the area of the other land uses converted to the forest lands during the time period of 2000-2012. It is encoded as " 1 " if there is a gain, but "0" otherwise. The other major third layer is the YEAR FOREST COVER LOSS, defined as a change from a forest to non-forest state. It is encoded as either 0 (no loss) or else a value in the range of $1-17$, representing loss detected primarily in the year 2001-2018, respectively. It is also important to 
note that besides the mapped areas, there also are areas with no data, created by the presence of clouds or not.

The data on TREE COVER in the year 2000 for the Central Togo were downloaded and retrieved in the ArcGIS Pro_2.3, and then Geo-referenced. In order to include all the classes considered in the FAO's classification [13], we reset the canopy closure to 10 classes for the mapping. These classes include the percentage canopy closure above 40, the percentages comprised between $10-40,5-10$, and finally the percentage canopy closure below 5 . The area in hectare for each class (e.g., the percentage of canopy closure ranging from 0 to 100) was calculated using the ArcGIS ZONAL GEOMETRY Table tools, and a mapping resolution of 1 kilometer.

Regarding the assessment of the effectiveness of the forestry administration we have overviewed the forest administration in the Central Togo, and examine its links with the International forestry administration. Our ultimate aim is to determine factors that have hindered the implementations of the forest land conservation's programs.

\section{Results}

\section{The spatial data analysis}

The Hansen/UMD/Google GIS data have allowed the mapping of the vegetation cover of Central Togo (Figure 1) and estimating the areas of the vegetation cover (Table 1). The total land area mapped for Central Togo in the year 2000 when the data were collected was estimated to 1,078,195.33 hectares. From Table 1 and according to the FAO 2000 definition of forest classes we could characterize the vegetation cover for the study area and calculated the classes land areas (Table 2).

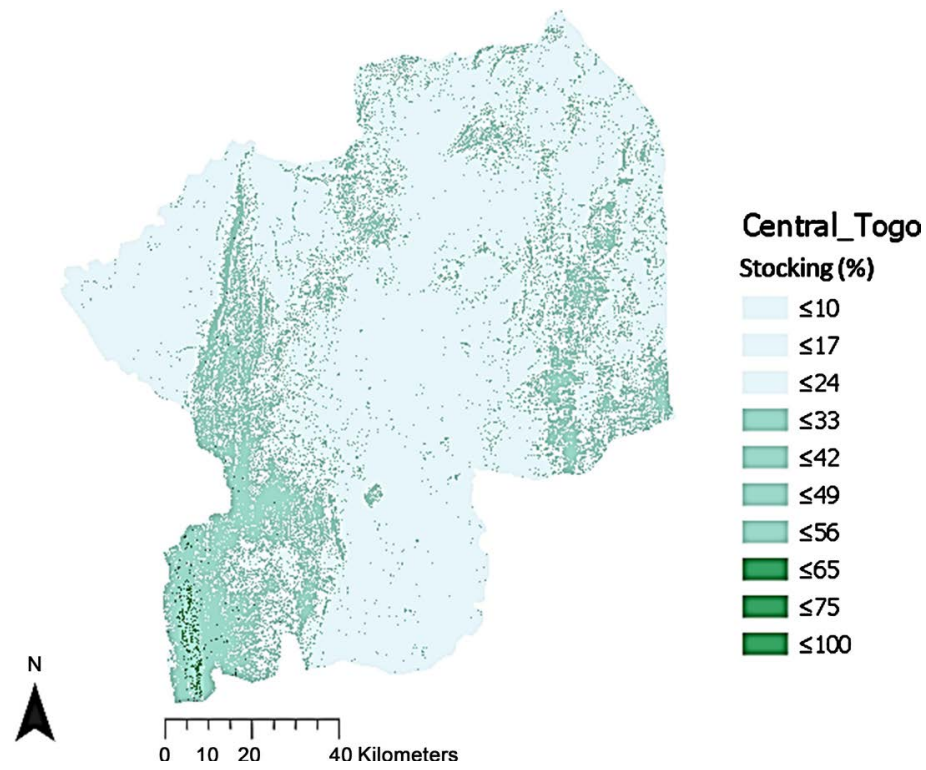

Source: UMD-Hansen-Google data.

Figure 1. Distribution of vegetation cover in the Central Togo. 
Table 1 . The area for each tree canopy closure class (0\% through $100 \%)$.

\begin{tabular}{|c|c|c|c|c|c|c|c|c|c|c|c|}
\hline \multirow{2}{*}{$\begin{array}{c}\text { Shocking } \\
\text { (\%) }\end{array}$} & \multicolumn{2}{|c|}{ Area $^{*}$} & \multirow{2}{*}{$\begin{array}{c}\text { Stocking } \\
(\%)\end{array}$} & \multicolumn{2}{|c|}{ Area ${ }^{*}$} & \multirow{2}{*}{$\begin{array}{c}\text { Stocking } \\
(\%)\end{array}$} & \multicolumn{2}{|c|}{ Area $^{*}$} & \multirow{2}{*}{$\begin{array}{c}\text { Stocking } \\
(\%)\end{array}$} & \multicolumn{2}{|c|}{ Area $^{*}$} \\
\hline & $\operatorname{Map}\left(\mathrm{m}^{2}\right)$ & Field (ha) & & $\operatorname{Map}\left(\mathrm{m}^{2}\right)$ & Field (ha) & & $\operatorname{Map}\left(\mathrm{m}^{2}\right)$ & Field (ha) & & $\operatorname{Map}\left(\mathrm{m}^{2}\right)$ & Field (ha) \\
\hline 0 & 0.00 & 641.00 & 26 & & 0.00 & 51 & 0.00 & 4201.00 & 76 & 0.00 & 8.00 \\
\hline 1 & 0.00 & 2108.00 & 27 & 0.01 & $10,619.00$ & 52 & 0.01 & 5010.00 & 77 & 0.00 & 7.00 \\
\hline 2 & 0.00 & 94.00 & 28 & 0.02 & $24,586.00$ & 53 & 0.00 & 46.00 & 78 & 0.00 & 17.00 \\
\hline 3 & & 0.00 & 29 & 0.03 & $30,651.33$ & 54 & 0.00 & 2801.00 & 79 & 0.00 & 4.00 \\
\hline 4 & 0.00 & 413.00 & 30 & 0.00 & 8.00 & 55 & 0.00 & 3034.00 & 80 & & 0.00 \\
\hline 5 & 0.00 & 3761.00 & 31 & 0.00 & 1442.00 & 56 & 0.00 & 789.00 & 81 & 0.00 & 3.00 \\
\hline 6 & 0.01 & 5166.00 & 32 & 0.00 & 2842.00 & 57 & 0.00 & 322.00 & 82 & 0.00 & 1.00 \\
\hline 7 & 0.00 & 26.00 & 33 & 0.01 & 6669.00 & 58 & 0.00 & 585.00 & 83 & 0.00 & 2.00 \\
\hline 8 & 0.01 & 6657.00 & 34 & 0.00 & 327.00 & 59 & 0.00 & 1148.00 & 84 & & 0.00 \\
\hline 9 & 0.00 & 4751.00 & 35 & 0.00 & 2.00 & 60 & 0.00 & 389.00 & 85 & 0.00 & 1.00 \\
\hline 10 & 0.00 & 1260.00 & 36 & 0.01 & 8661.00 & 61 & 0.00 & 74.00 & 86 & & 0.00 \\
\hline 11 & 0.00 & 6.00 & 37 & 0.04 & $36,033.00$ & 62 & 0.00 & 288.00 & 87 & 0.00 & 2.00 \\
\hline 12 & 0.28 & $281,430.00$ & 38 & 0.00 & 10.00 & 63 & 0.00 & 137.00 & 88 & & 0.00 \\
\hline 13 & 0.03 & $31,374.00$ & 39 & 0.01 & $10,384.00$ & 64 & 0.00 & 84.00 & 89 & & 0.00 \\
\hline 14 & 0.00 & 30.00 & 40 & 0.01 & 9701.00 & 65 & 0.00 & 26.00 & 90 & 0.00 & 6.00 \\
\hline 15 & 0.00 & 3.00 & 41 & 0.01 & 5475.00 & 66 & 0.00 & 15.00 & 91 & & 0.00 \\
\hline 16 & 0.32 & $323,091.00$ & 42 & 0.00 & 564.00 & 67 & 0.00 & 35.00 & 92 & & 0.00 \\
\hline 17 & 0.01 & $10,134.00$ & 43 & 0.01 & 5465.00 & 68 & 0.00 & 21.00 & 93 & 0.00 & 1.00 \\
\hline 18 & 0.02 & $15,641.00$ & 44 & 0.01 & 5780.00 & 69 & 0.00 & 9.00 & 94 & 0.00 & 0.00 \\
\hline 19 & 0.00 & 693.00 & 45 & 0.00 & 2837.00 & 70 & 0.00 & 72.00 & 95 & 0.00 & 0.00 \\
\hline 20 & 0.14 & $139,809.00$ & 46 & 0.00 & 347.00 & 71 & 0.00 & 93.00 & 96 & 0.00 & 0.00 \\
\hline 21 & 0.00 & 2482.00 & 47 & 0.03 & $25,571.00$ & 72 & 0.00 & 76.00 & 97 & 0.00 & 0.00 \\
\hline 22 & 0.01 & $14,453.00$ & 48 & 0.01 & $10,953.00$ & 73 & 0.00 & 29.00 & 98 & 0.00 & 0.00 \\
\hline 23 & 0.00 & 26.00 & 49 & 0.00 & 4404.00 & 74 & 0.00 & 19.00 & 99 & 0.00 & 0.00 \\
\hline 24 & 0.01 & $11,144.00$ & 50 & 0.00 & 115.00 & 75 & 0.00 & 19.00 & 100 & 0.00 & 0.00 \\
\hline 25 & 0.00 & 182.00 & & & & & & & & & \\
\hline
\end{tabular}

Source: UMD-Hansen-Google data. ${ }^{*}$ The areas in square meters represent the areas on the map; the ones in hectares represent the areas in the field. These latter are obtained using the mapping resolution of one kilometer.

Table 2. Classification of vegetation cover in Central Togo.

\begin{tabular}{cccc}
\hline Vegetation cover type & Percentage of canopy closure (\%) & Area (ha) & Percentage total area \\
\hline Tropical deciduous and semi-deciduous closed forests & Above 40 & 80,885 & 7.50 \\
Tropical fragmented or degraded forests & 10 to 40 & $972,433.33$ & 90.19 \\
Tropical woody savannas & 5 to 10 & 17,860 & 1.66 \\
Croplands, grassland and non-woody wetland & below 5 & 7017 & 0.65 \\
Total & & $1,078,195$ & 100 \\
\hline
\end{tabular}

Source: UMD-Hansen-Google data. 
Forest administration at the Central Togo, national as well as global levels

The forestry administration in the country depends on whether the forest land is public owned, belongs to the collectivities, or it is classified as a private forest land. The national forests, about 793,300 ha [14], 14 percent of the country land area are administrated by the Office of the Forest Management and Development (ODEF), The Forest belonging to the collectivities and the private are administrated by the Office of the Forests (DEF). Broadly, these forest offices are represented throughout the country by five regional offices for DEF, and four regional offices for ODEF. The DEF operates at local levels through the prefectural offices. Else, like in most countries in the sub-region of West Africa the forestry programs and projects in Togo result from the international conventions and protocols signed and ratified by the countries. These major conventions and protocols include importantly, the United Nations Convention on Climate Change (UNFCCC) and the Kyoto protocol, the United Nations Convention on Biodiversity, and finally the United Nations Convention on desertification [15]. As Ivanova [16] clearly stated: "the United Nations Environmental Program (UNEP) had assisted developing countries in creating environmental laws and developing soft-law guidelines for a wide range of sectors." Other evidence of the dependency of the national forest programs on the international conventions and protocols is the existence of many focal points within the Ministry of the Environment and Forest Resources whose principal mandates are the implementation of emergent United Nations' forests and other environmental related initiatives. Below, we examine some plans, programs and/or projects administrating Togo's forestry sector.

The first one is the National Forestry Action Plan (PAFN), the major forestry planning document of the country. It originates from the FAO Tropical Forest Action Program (TFAP) created in 1985 to stop tropical deforestation [17]. Togo joined the Program in 1987. A country's Forestry Action Plan was issued in 1994, but could not be implemented due to many constraints. The PAFN was reactivated in 2011 with ultimate challenges summarized as follows: the recovery of the vegetation cover potential, the country self-reliance regarding the forest products supply, and the local people's livelihood enhancement. The second important program the REDD program, was launched in 1997 during the Kyoto Protocol as an extension of the United Nations Framework Convention on Climate Change (UNFCCC) of 1992, to reduce the emissions of the greenhouse gases through forest conservation. According to Pfaff and Lawlor [18] the developed countries would finance the program in order to meet their targets for reduced emissions. The same authors asserted that the reviews of many other alternatives to REDD+ also concluded that the REDD+ program constitutes the least expensive options for tropical forest conservation because the tropical ecosystems have less potential for other land uses, principally the agriculture which is very destructive of the land. Togo joined the REDD+ Program in 2004, and is actually working through the first phase which is the stage of Readiness and the 
strategies' setting. The remaining phase is the pilot demonstration which will ultimately lead to the Monitoring, the Reporting, and the Validation (MRV) of the program. The other important conservation program in Togo is issued from the convention on biological conservation signed in 1992, and ratified by the country in 1995 [19]. The program has allowed the country to set in place a national monography on biological diversity and a strategic document on the conservation and management of the biodiversity.

It is clear that the REDD+ and the biological conservation programs are the implementation of the international forestry programs whose major objectives are described above. Ivanova [16] acknowledges the UNEP's achievement for each of the mandates it had assigned. Unfortunately, the international forestry programs do not aim at implementing the programs and activities at national or local levels, this constitutes the responsibilities of the countries [15]. The UNFCCC concerns for local communities and indigenous peoples in Agenda 21 [20] were reiterated at the Conference of Parties in 2017 [21]. The most relevance requirement of the COP 23 towards the countries member of REDD+ is to promote the sustainable forest management. One needs to acknowledge that the sustainable forest management does not exclude the traditional role of the forests, rather it must be reinforced, or an alternative that substitutes for this traditional role must be identified and implemented. As we will raise it in the discussions, it is obvious that we cannot successfully implement forestry programs without accounting for local people's interests or needs.

Unlike the CBD and the REDD+ programs the PAFN addresses the forestry issues in a holistic manner regarding its assigned challenges discussed above. But our investigations during this current study reveal that none of these challenges has been realized. For instance both GIS data and panel data [22] analyses are concordant that the deforestation is still ongoing in Central Togo, the country still relies on import to satisfy its wood consumption [14], and finally, the poverty level in the region is the second highest of the country [23]. There has not been an evaluation of the updated 2011 PAFN, but the analysis of its performance from 1994 up to 2011 helps to identify what had hindered its implementation, which concern will be reintroduced in the chapter reserved to the discussions.

\section{Discussions}

\section{Forest definition versus the inventory parameters' threshold}

This subject has been wildly discussed in the literature [11]; and [10], but we have reintroduced it in here to show that what is required is not to improve forest definition, but rather a sound and responsible forest management practice. Therefore we discuss here the effects of limiting forest land classification to one inventory parameter (or very few) to define forest ecosystems, and the reverse effects of wrong setting the inventory parameters' thresholds on forest ecosystems. 


\section{Forest inventory parameters and forest definitions}

The forest land area data from Central Togo (Table 1) is recapitulated below (Table 3). It can be noticed that assigning the FAO [13] threshold of $40 \%$ crown closure for the land classification permitted to estimate the closed forest land area to 80,885 hectares, and the fragmented and degraded forest land area to 972,433.33 hectares. But applying the United Nations Framework Convention on Climate Changes (UNFCCC)'s of 30\% crown closure [10] estimated the closed forest land area to 156,956 hectares and the fragmented and degraded forest land area to $896,362.33$ hectares. This changing in the canopy closure threshold from $40 \%$ to $30 \%$ has favored the increase of the closed forest land area but has reduced the area occupied by the fragmented and degraded forest land area by the same amount: 76,071 hectares, the last column (Table 3). Thus we join Chazdon et al. [10] to raise the question of "what the forest is", or how to draw the line between each vegetation cover type. Otherwise stated, to which class belong the 76,071 ha of forest lands.

In fact, recent definitions of forest stress on the inventory parameters as would outline Chazdon et al. [10]. Importantly these parameters are the canopy ground cover, more than $10 \%-40 \%$ coverage or $10 \%-30 \%$ coverage depending on whether one adopts the FAO or the UNFCCC criteria; the minimum diameter at breast height $(\mathrm{dbh})$, usually $10 \mathrm{~cm}$. The minimum stand size and the height of the tree at maturity are also considered but would not be discussed here because they raise other difficult issues notably the ecosystem time-space scaling which are not really relevant to our interest. The FAO classification has gone further to distinguish between the closed forest, more than $40 \%$ of the canopy closure, from the open and degraded forest where the canopy covers between $10 \%$ and $40 \%$. This consideration of the inventory parameters threshold in the forest definition is the starting point of the confusion. Originally, the inventory parameters are developed neither for land assessment nor for conservation but for the management purposes. For instance, thinning a stand to a number of trees (e.g., stocking) helps the forester to make sound decision about how to treat the stand [24]. Setting the parameter threshold should be understood as

Table 3. Comparison of the FAO forest land class definition to that of the UNFCCC.

\begin{tabular}{|c|c|c|c|c|c|}
\hline \multirow{2}{*}{ Forest classes } & \multicolumn{2}{|c|}{ FAO definition } & \multicolumn{2}{|c|}{ UNFCCC definition } & \multirow{2}{*}{ Change } \\
\hline & crown coverage & Area (ha) & crown coverage & Area & \\
\hline Closed tropical forest & more than $40 \%$ & 80,885 & more than $30 \%$ & 156,956 & $-76,071$ \\
\hline Fragmented forests & $\begin{array}{c}\text { Between } 10 \% \text { to } \\
40 \%\end{array}$ & $972,433.33$ & $\begin{array}{c}\text { between } 10 \% \text { to } \\
30 \%\end{array}$ & $896,362.33$ & 76,071 \\
\hline Woody savannas & $\begin{array}{c}\text { more than } 5 \% \text { to } \\
10 \%\end{array}$ & 17,860 & more than 5 to $10 \%$ & 17,860 & 0 \\
\hline Others $^{*}$ & 0 to $5 \%$ & 7017 & 0 to $5 \%$ & 7017 & 0 \\
\hline Total & & $1,078,195.33$ & & $1,078,195.33$ & \\
\hline
\end{tabular}

${ }^{\star}$ Others $=$ Croplands, grasslands, non-woody wetlands; Source: UMD-Hansen-Google data. 
either to optimize the stand production in the case of forest stand management, or to preserve the integrity of the functioning of forest ecosystems. Therefore, like in the traditional sylvicultural practices setting the tree crown closure threshold should aim at reaching the management objectives such as timber management, conservation, climate change mitigation, and earth stewardship as outlined by Chazdon et al. [10]. Attempting to harmonize these parameters' threshold to reach different management objectives is also another source of confusion. The timber manager emphasizes on the tree stem quality and therefore prefers stand with high tree density. The wildlife manager emphasizes on the quantity and quality of the fodder thus manages the stand with abundant grasses and herbs, thus stands with lower tree density. An agro forester manages stands with different patterns of combination of perennials and crops. The forest manager for carbon sequestration seeks to store as much as biomass in the stand, no matter the quality of the wood. All these types of land uses are present during a forest land assessment and cannot be separated using just one or few inventory parameters' threshold.

To decide if an ecosystem is a forest ecosystem or another type of vegetation cover requires the knowledge of additional vegetation cover characteristics principally the stand species structure and composition, the life history of the site, the mean annual biomass increment, and so on. Therefore a forest ecosystem can be defined in respect to its climax prior to the disturbance. We thus agree with Richards [25] definition of tropical rain forest as: "Evergreen, hygrophilous in character, at least $30 \mathrm{~m}$. high, but usually taller, rich in thick-stemmed lianas and in woody as well as herbaceous epiphytes." The same author when relaying Chevalier [3] defines a savanna forest as: "more or less leafless during the dry season, rarely evergreen, xerophilous in character, often much less than $20 \mathrm{~m}$. high, park-like, very poor in underwood, lianas and epiphytes, rich in terrestrial herbs, especially grasses." The definitions stress on biotic parameters because any other conditions necessary to define an ecosystem including both edaphic and climatic ones are assumed to be fixed and thus cannot be altered as long as the disturbance is less than the threshold. Also, because of its cybernetic or self-regulatory behavior, following a minor disturbance, a forest ecosystem would continuously tend to return to the initial state (if a climactic forest), or initial trajectory (if an ingrowth or a secondary forest) [26] [27]. Thus, the discrepancy in the assessment results is to be attributed to land classification based on few inventory parameters' thresholds which depend on assigned management objectives, but not on the changing in forest definitions. These inventory parameters' thresholds are just management tools when properly developed and implemented helps to reach the objectives of forest management. New classifications using new inventory parameters' thresholds will emerge as long as new policies are developed to address emergent issues. Therefore, a constant and consistent definition (identification) of forest ecosystem, for efficient monitoring and assessment, requires forest management practices that continuously make 
available fine local data to supplement for the remote sensing periodical surveys.

The reverse effects of a wrong setting of the inventory parameters thresholds on forest conservation

In fact, there is evidence in the Central Togo of the existence of land without forest, land where the vegetation cover is a mixture of forest and the savanna (e.g., fragmented and degraded forests), and finally the existence of closed forest (Figure 2). From an historical perspective, the valleys of the Atakora chain of mountains which used to be forested lands three decades earlier are currently occupied by villages and farms. It is unsure the forests will revert at the abandoning of farming because the erosions have carried away the topsoil leaving in place the bare rocks.

From this example we explore the extent at which these inventory parameter thresholds induce or could induce deforestation or forest degradation. Often countries or policies decide to increase or reduce such or such inventory parameter threshold to optimize some particular goods or services from the forest [10]. Such practices not only lead to the discrepancy on the assessment results discussed previously, but also are they risky for most tropical countries where wild fire, illegal tree cutting, and water and soil conservation still constitute important challenging issues. The wrong setting of the threshold leads to reverse effects on our conservation effort. For instance, setting the crown cover threshold very low may appear as legitimating wood cutting for illegal cutter because he thinks he still has the right to cut as long as the threshold is not attained. The

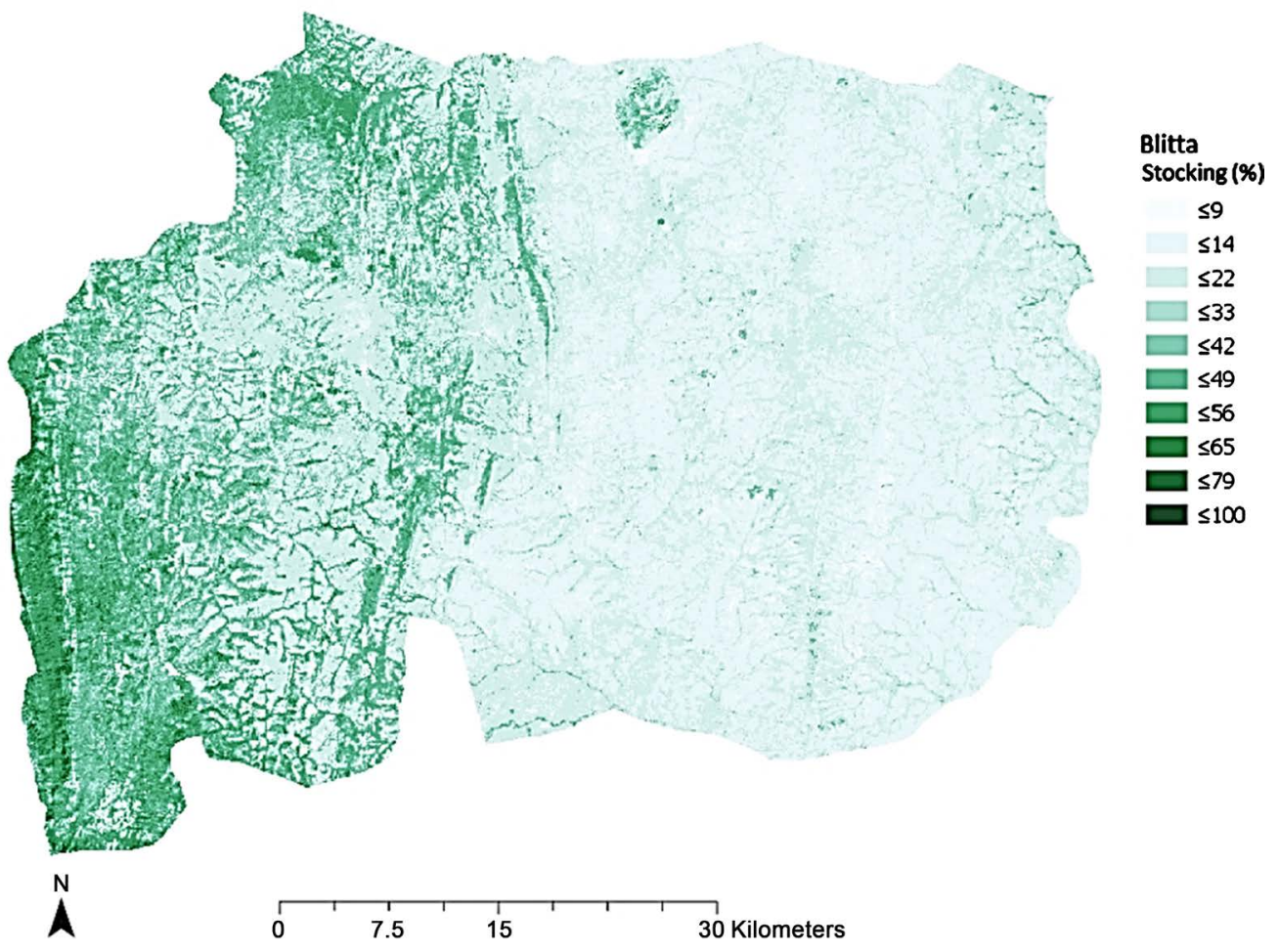

Source: UMD-Hansen-Google data.

Figure 2. Vegetation cover distribution in the southern of central Togo. 
associated consequences of a heavy removal of the vegetation cover from a landscape are wild fire in area prone to fire, or to water and soil conservation difficulties in the steep sloped mountainous areas wildly discussed in the literature [11]. In fact, from our study area, the Assoukoko forests (Figure 2) appear homogeneous, but visits to the site show that the understory of most of these forests is occupied with cocoa and coffee farms. Still these forests deserve to be classified as closed forests because the canopy cover is over 40 percent (e.g., FAO classification) or 30 percent (UNFCCC classification). We need to understand that tropical deforestation and forest degradation are issues at high stake because the observed effects cannot be specifically attributed to the shifting in the classification methods; they are cumulative effects of many deforestation and forest degradation factors. To provide a holistic recommendation on deforestation and forest degradation, all these factors must be accounted for. The most important factor that constitutes the next of the concerns in this article is the administration and the governance of the forest resources.

Conservation constraints relative to the forestry administration

In this sub-chapter we present the forest resources as common-pool resources and show that their administration cannot be dealt with at one particular level of environmental concerns (e.g., global level as opposed to regional and local environmental concerns).

Forests as the common-pool resources

Our definition of a common-pool resource is borrowed from Ostrom [28] [29]

"A common-pool resource, such as a lake or ocean, an irrigation system, a fishing ground, a forest, the internet, or the stratosphere, is a natural or man-made resource from which it is difficult to exclude or limit users once the resource is provided by nature or produced by humans. One person's consumption of resource units removes those units from what is available to others. Thus, the trees or fish harvested by one user are no longer available for others." Ostrom (1994, p3-49; and 1998, p4)

To show the common-pool resource character of the forest, we categorize the forest users into three groups (Table 4), even if there may exist many intermediaries along the spectrum.

These groups include: 1) the international communities such as the United Nations, concerned with global environmental issues specifically, global deforestation, the climate change, and some other diverse conservational issues; 2) the Regional community institutions which are concerned with the regional environmental issues like biodiversity conservation, desertification, soil and water conservation, and so on ... and finally; 3 ) the last group, or the forest dwellers or the local people concerned mostly with cultural or subsistence forestry practices. It is important to realize (Table 4) that the lines between the users groups are very difficult to draw. The groups may overlap in terms of sharing the resources or services, which is a characteristic of the common-pool resources. It is equally 
important to notice that the list of the uses and services, and that of the users (Table 4), and the definition of the user groups are not presented here in an exhaustive way. We just intend to show the common-pool resources character of the forest resources (e.g., forest goods as well as services).

The current forestry administration and its flaws

In chapter 3) relative to the presentation of the analyses results, we presented some efforts undertaken to save tropical forests. Here we discuss the factors that have impeded the successful implementation of these plans, programs, and projects. A close look on the forest administration in Togo (Table 5) reveals that there are no real incentives available to local users of the forest regarding forestry

Table 4. Some uses and services of the forest products.

\begin{tabular}{cc}
\hline Uses and services & The user groups \\
Carbon sinks & World community \\
Water quality/quantity conservation & Reginal/national community \\
Soil conservation/stabilization & \\
Industrial wood & \\
Land & Cultural practices \\
Fuel wood & \\
Recreational resources (tourism, games) & \\
Food (games, fruits, and tuber) & \\
Tooth stick (roots, branches) & \\
Divinities worshipping &
\end{tabular}

Table 5. Major constraints to forestry policies implementation in Togo.

\begin{tabular}{ll}
\hline No & \multicolumn{1}{c}{ Various issues } \\
\hline 1 & The absence of legislation on land tenure until recently (e.g., 2018) \\
2 & Absence of forestry management plans \\
3 & Forest lands' conversion to other land uses for multiple reasons \\
4 & Low investment in forest planting \\
5 & Wild bush fire \\
6 & Very few number of forestry employees \\
7 & Inadequate forest laws and awkward implementation of the existing ones \\
8 & $\begin{array}{l}\text { Lack of institutional collaboration leading to none or bad implementation of programs } \\
\text { activities, or projects }\end{array}$ \\
\hline
\end{tabular}

Source: Togo-PAFN, 2011. 
policies' implementation besides anniversary celebrations (e.g., Arbor Day and Earth Day ...), prizes distribution, some training workshops, and seedling distribution to landowners. The common policy instruments are the regulations and policing to limit access to the forest lands. Even at the national level, significant incentives are very few and available just for limited projects and programs like the management of the Haho-baloe forest plantation's ITTO project, the project to promote sylvicultural practices in Yoto, and some NGOs initiatives [14]. We recapitulate Table 5 saying that the failure to forestry plan, programs, and projects implementation is associated to various sources including socioeconomics, institutional, socio-politics and technical constraints.

At the international level we also recapitulate here (Figure 3) the mandates of the international forestry program discussed earlier.

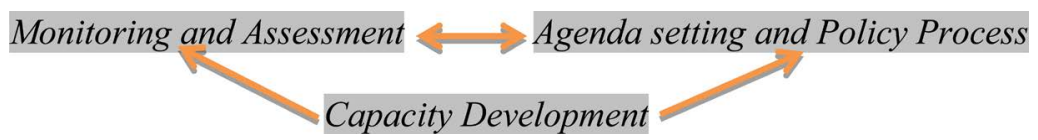

Figure 3. Different mandates of the UNEP as an anchor institution (sources: Ivanova, 2005).

Analysists, particularly Ivanova [16] denounces the flaws in the UNEP's performance. Some of them are: 1) the fragmentation and duplication of the same programs/activities across the eight divisions of the UNEP and also across the other United Nations' agencies, the multilateral institutions, and the Non-Governmental Organizations; 2) the scarcity of the resources available to the UNEP, 3) the misuse of the United Nations financial resources by the countries, and finally, 4) the ambition of the UNEP of becoming reactive in the field of capacity building instead of remaining a proactive agency. However, as raised above, the implementation of the programs and activities at national or local levels constitutes the responsibilities of the countries. All these point out the major difficulties faced by the actual forestry administration which may be regrouped in two points: the difficulty of satisfying the multitude of interests that exist along the way from the local environmental level to the global one, and the commons dilemma induced by the distortion of the international forestry administration policy implementation. Regarding the common interest identification, from the local environmental concerns to the local ones the stakeholders are numerous and the interests may not be of the same nature. Problem arises as we all focus on the mitigation of global warming as the "common interest", with a tacit assumption that the issues at the other environmental concern levels have been taken care of. This is not true they have just been ignored or at least minimized at the expenses of the global warming, the identified common interest. The consequence is today tangible in the field, ineffective policies. A close look on the functioning of the current forestry administration shows that it has been established in accordance to the "central direction" model. Indeed, this type of top-down administration was developed by the proponents to enable the equita- 
ble and rational uses of the resources as Ostrom Stated below.

Since the influential article by Garrett Hardin [30], "the tragedy of the commons" has been used as a metaphor for the problems of overuse and degradation of natural resources including the destruction of many fisheries, the overharvesting of timber, and the degradation of forests. Many policy analysts, scholars, and public officials agree with Hardin's conclusion that the participants in a commons dilemma are trapped in an inexorable process from which they cannot extract themselves. External authorities are presumably needed to impose rules and regulations on local users since they will not do this themselves (Ostrom, 1998, p1).

Ostrom [29] had already contended the central direction governance model's prescription asserting that the theoretical foundations of the model are wrong. The results from our conservation policies constitute evidence to the visionary position of Ostrom. The actual forestry administration seems not to be able to account for the interest of all. For instance, factors such as agricultural land expansion, fuel wood supply, branches and other parts of the trees collection for various uses, forestry for divinities worshiping, are well documented as major agents of deforestation and forest degradation [11] [31]. These practices for subsistence constitute important preoccupations to individuals who face these problems in a daily basis, but our forestry policies have given limited consideration to these issues urgency. It is necessary to acknowledge that the local user of forestry resources must have an incentive to abandon the traditional practice and adopt an introduced innovation [29], that is, the conservation.

Else, the proponents of the central direction administration model [30] also think it could eradicate the "commons dilemma". Unfortunately, this has not been the case either. There are many examples to elucidate this sad fact. At the national level in Togo, the total expenditure in forestry sector from 2000 to 2008 is estimated to 2274 million Fcfa [14j]. Just 839 million Fcfa or $36.9 \%$ of the expenditure has been invested on forestry activities, the remaining $63.1 \%$ were used for the project functioning and administration works which is not right. In 2004, a joint project of the Royal Swedish Academy of Agriculture and Forestry (KLSA), the FAO, and African Academy of Science (AAS) [32] clearly stated that the corruption and illegal forest activities had rendered ineffective the African Public Forest Administration (PFA). According to Ivanova [16] the UNEP's financial structure enabled countries to pursue their own interests, rather than the common good. Finally, Chazdon et al. [10] also raised the point that countries had changed the inventory parameter thresholds in their national legal forest classification to benefit more funding from the Clean Development Mechanism (CDM) program. Clearly, in addition to the difficulty of dealing with the multiplicity of the interests around the forest resources, the actual forestry administration faces the concern of the commons dilemma. Like in agricultural goods' supply to the market, the forestry program implementation also suffers from the 
distortion in the implementation of its program. The question of how to make the financial resources available for the implementation of plans, programs, projects and activities remains issues of serious challenge. Even if these two issues, the common interest and the commons dilemma are all of great interest, we prefer not to elaborate further on the latter one regarding the scope of this study.

The question around the implication of all stakeholders in conservation processes constitutes a preoccupation of the forestry administration because of its concern for indigenous people and local communities. But, we need to clearly understand that the dispositions included in the United Nations Declarations on sustainable development [20], principally in Chapter $3.7 \mathrm{a}$ and $3.7 \mathrm{~d}$, and in Chapter 3.8, are not calls for help on behalf of local communities. This cannot either be limited just to the share of their valuable knowledge in the fight against climate change and its impact [21]. Other dispositions (e.g., 26.1 of the Declarations) call also for-the respects of the cultural integrity and the rights of indigenous people. This implies that the traditional forestry practices must be accounted for in our conservation policies. We need to reiterate that these dispositions constitute paths to successful conservation policies' designing as well as their implementation. Thus, we ask ourselves that how the voices of so many authors importantly Fairhead and Melissa [33], Ostrom [29] and others have not been heard. The deforestation and forest degradation issues need to be reframed or at least rethought. We urgently call for the simplification of the mandates of the forestry program. Importantly, the mandate concerning-policy processes and agenda setting - needs to be profoundly revised. For, what is the use of so frequent international gatherings, at high cost, and finally to come out each time with non-binding agreements? Simplified policy processes that take place at local levels (e.g., counties, villages, collectivities, individual private land owners levels) to define forest management plans in link with site specific stakeholders' interests, importantly that of the most dependent on forest resources, are highly required. Models exist in the fields of social sciences (e.g., the self-organized resources governance systems of Ostrom) [34] as well as in biological sciences (e.g., hierarchical concept of an ecosystem of O'Neill) [35], that could serve to successfully address the concerns. Instead of being conflictual, the interests need to be connected and embedded into each other through hierarchical patterns.

\section{Conclusions}

In this article we assess some constraints to tropical forest conservation and to the successful monitoring and assessment of the land use and cover change, principally the constraints relative to forest definition of the inventory parameters' threshold, and to the governance. The methodologies to study the constraints to the forest definition and the inventory parameters thresholds are based on the analysis of UMD-Hansen FAO 2000 GIS data available in the Internet. The TREE COVER (dataset layer) in the year 2000 for the Central Togo 
was downloaded from the global dataset UMD-Hansen-Google, retrieved in the ArcGIS Pro_2.3, and then Geo-referenced to produce the Central Togo map. The vegetation cover classification was based primarily on the percentage of canopy closure. The area in hectare for each class was calculated using the ArcGIS ZONAL GEOMETRY Table tools, and on a mapping resolution of 1 kilometer. Then we compare the classification of the forest land using the FAO's classification based on canopy closure threshold of $10 \%-40 \%$ with that of the UNFCCC criteria of $10 \%-30 \%$ canopy closure threshold. The difference in the assessment results from the two classification types leads to conclude that confusion in forest monitoring and assessments is due to classification based on few inventory parameter thresholds which are management objectives oriented. These inventory parameter thresholds are efficient tools for forest managers to make a sound decision on sylvicultural practices, but they cannot substitute for what forest is. To define a forest land or to decide if a vegetation cover is forest ecosystem (e.g., a mature forest or ingrowth), a savanna, or other types of vegetation cover, requires the knowledge of additional ecosystem characteristics. This leads to recommend sylvicultural practices that could provide continuous fine local data to supplement for periodical remote sensing surveys in the forest resources assessment.

Our narrative analysis of the effectiveness of the forestry administration has overviewed the forest administration at the regional Central Togo and national levels, and examined its links with the International forestry administration. Our ultimate aim is to determine factors that have hindered the implementations of the forest land conservation policies. The major plan, program, and project at the national level are the National Forest Action Plan, the REDD+, and the Program on Biodiversity Conservation. At the international level the institutionalized program is the United Nations Environmental Program. The failure to forestry policies' implementation has been commonly associated with the socio-economics, institutional, socio-politics and technical factors. The major international administrative constraints are the heavy administrative procedure, the diversion of the international forestry funds to personal uses. Further, this article demonstrates that the forestry administration is suffering from issues relative to the common-pool resources' administration which are how to satisfy the interest of all resources users, and how to get rid of the common dilemma. Regarding the first point, the current forestry administration has been biased of local people interests by not properly accounting for subsistence forestry practices which constitute the major factors of deforestation and forest degradation. Regarding the second point, the difficulty to cope with the question around the common dilemma, the administration is still pervasive with the diversion of the international forestry funds to personal country or private uses, the question of under-table, money laundry and bribery. Thus, we call for the simplification of the forestry administration with an emphasis on the development of local forestry. This consists of simplified policy processes, gathering all stakeholders, at 
local level (e.g., counties, villages, private landowners levels), to define forest management plans with the consideration of the interests of all users, primordially, that of the most dependent on forest products. These interests rather being conflictual need to be embedded in one other with harmonious collaboration of the stakeholders.

\section{Conflicts of Interest}

The authors declare no conflicts of interest regarding the publication of this paper.

\section{References}

[1] Richards, P.W. (1952) The Tropical Rain Forest and Ecological Study. Cambridge University Press, Cambridge, 2.

[2] Longman, K.A. and Jenik, J. (1987) Tropical Forest and Its Environment. Longman Scientific and Technical, Harlow, 1-7.

[3] Chevalier, A. (1933) Geo-Botanical Territories of West and North Africa, and Their Subdivisions. Bulletin of the Botanic Society of France, 80, 4-26. https://doi.org/10.1080/00378941.1933.10833810

[4] Fairhead, J. and Leach, M. (1995) False Forest History, Complicit Social Analysis: Rethinking Some West African Environmental Narratives. World Development, 23, 1023-1035. https://doi.org/10.1016/0305-750X(95)00026-9

[5] Lamouroux, M. (1969) Notice explicative de la carte pédologique du Togo. ORSTOM, Paris, 86 p.

[6] Togo-PFT (2011) Forestry Politics of du Togo, Togo-FAO.

[7] Togo-RPP (2013) Proposition de Mesures pour l'Etat de préparation (RPP). (FCPF).

[8] Togo-IFN (2015) National Forest Inventory, Togo-GIZ.

[9] Angelsen, A. and Kaimowitz, D. (1999) Rethinking the Causes of Deforestation: Lessons from Economic Models. The World Bank Research Observer, 14, 73-98. https://doi.org/10.1093/wbro/14.1.73

[10] Chazdon, R.L., Brancalion, P.H.S., Laestadius, L., Bennett-Curry, A., Uckingham, K., Kumar, C., Moll-Rocek, J., Vieira, I.C.G. and Wilson, S.J. (2016) When Is a Forest a Forest? Forest Concepts and Definitions in the Era of Forest and Landscape Restoration. Ambio, 45, 538-550. https://doi.org/10.1007/s13280-016-0772-y

[11] Sasaki, N. and Putz, E.F. (2009) Critical Need for New Definitions of "Forest" and "Forest Degradation" in Global Climate Change Agreements. Conservation Letters, 2, 226-232. https://doi.org/10.1111/j.1755-263X.2009.00067.x

[12] Hansen, M.C., Potapov, P.V., Moore, R., Hancher, M., Turubanova, S.A., Tyukavina, A., Thau, D., Stehman, S.V., Goetz, S.J., Loveland, T.R., Kommareddy, A., Egorov, A., Chini, L., Justice, C.O. and Townshend, J.R.G. (2013) High-Resolution Global Maps of 21st-Century Forest Cover Change. Science, 342, 850-853. http://earthenginepartners.appspot.com/science-2013-global-forest https://doi.org/10.1126/science.1244693

[13] FAO (2001) Table 47-1. FRA 2000 Global Land Cover Map Legend, Definitions and Representative Land Cover Types. http://www.fao.org/3/y1997e/y1997e1g.htm

[14] Togo-PAFN (2011) National Forest Action Plan of Togo, Phase 1 2011-2019, MERF, Togo. 
[15] Togo-REDD+ (2017) The Analysis of the Judiciary Framework, and Legislations Relative to REDD+ Implementation in Togo.

[16] Ivanova, M. (2005) Assessing UNEP as Anchor Institution for the Global Environment: Lessons for the UNEO Debate. Yale Center for Environmental Law and Policy, Yale University, New Haven, Working Paper No. 05/01, 11. https://www.academia.edu/1876627/Assessing_UNEP_as_anchor_institution_for_t he_global_environment_Lessons_for_the_UNEO_debate

[17] Burley, F.W. (1988) Tropical Forestry Action Plan Recent Progress and New Initiatives. In: Wilson, E.O. and Peter, F.M., Eds., Biodiversity, Academies Press (US), Washington DC, Chapter 45. https://www.ncbi.nlm.nih.gov/books/NBK219314

[18] Pfaff, A. and Lawlor, K. (2013) Learning on the United Nations Convention on Climate Change Resources, REDD. In: Encyclopedia of Energy, Natural Resources, and Environmental Economics, Elsevier, Amsterdam, 144-149.

https://www.sciencedirect.com/topics/earth-and-planetary-sciences/united-nationsframework-convention-on-climate-change

[19] Togo-REDD+ (2017) Analysis of the Judiciary Framework and Legislations Relative to REDD+ Implementation in Togo.

[20] UNFCCC-Agenda 21 (1992) United Nations Conference on Environment \& Development, Chapter 3.7a and 3.7d, and in Chapter 3.8.

[21] UNFCCC-COP 23 (2017) COP 23 Indigenous People and Local Communities. https://www4.unfccc.int/sites/NWPStaging/News/Pages/IPP-PreCOP23_Article.asp x

[22] Bassan, K.A., Kokou, K. and Sills, E. (2019) Linear Panel Data and Farming Cash Flow Analyses to Assess the Causes of Deforestation in the Upper Guinean Forest: Data and Evidence from the Prefectures of the Central Region in Togo. Journal of Natural Resources.

[23] Togo-DSRP-C (2009) Complete Strategic Document on Poverty Alleviation in Togo, INSEED, Togo.

[24] USDA-Forest Service: Forest Stand Density and Stocking: Concepts, Terms, and the Use of Stocking Guides.

https://archive.org/stream/CAT88885287/CAT88885287_djvu.txt

[25] Richards, P.W. (1952) The Tropical Rain Forest and Ecological Study, Chapter 15: Rain Forest, Deciduous Forest and Savanna. Cambridge Univ. Press, Cambridge, 315.

[26] O’Neill, P.V., DeAngelis, D.L., Waide, J.B. and Allen, T.F.H. (1986) A Hierarchical Concept of Ecosystem. Princeton University Press, Princeton, 35-71.

[27] Chazdon, L.R. (2008) Chance and Determinism in Tropical Forest Succession. In: Carson, W.P., Ed., Tropical Forest Community Ecology, Stefan A. Schnitzer \& Smithsonian Tropical Research Institute, Balboa, 387-396.

[28] Ostrom, E., Gardner, R., Walker, J., Agrawal, A., Blomquist, W., Schlager, E. and Yan Tang, S. (1994) Rules, Games, and Common Pool Resources. The University of Michigan Press, Ann Arbor, Chapter 1 and 2, 3-49.

https://doi.org/10.3998/mpub.9739

[29] Ostrom, E. (1998) Coping with the Tragedy of Common. In: Workshop in Political Theory and Policy Analysis Center for the Study of Institutions, Population, and Environmental Change, Indiana University, Bloomington, 4.

[30] Hardin, G. (1968) The Tragedy of the Commons. Science, 162, 1243-1248. 
https://doi.org/10.1126/science.162.3859.1243

[31] Hosonuma, N., Herold, M., De Sy, V., De Fries, R.S., Brockhaus, M., Verchot, L., Angelsen, A. and Romijn, E. (2012) An Assessment of Deforestation and Forest Degradation Drivers in Developing Countries. Environmental Research Letters, 7, 12. https://doi.org/10.1088/1748-9326/7/4/044009

[32] Owino, F. and Ndinga, A. (2004) Study on Forest Administration and Related Institutional Arrangements, Forest Resources International, KSLA, AFORNET, and FAO.

[33] Fairhead, J. and Leach, M. (1998) Reframing Deforestation: Global Analyses and Local Realities: Studies in West Africa. Global Environmental Change Series.

[34] Ostrom, E. (1990) Governing the Commons; the Evolution of Institutions for Collective Action. Cambridge University Press, Cambridge. https://doi.org/10.1017/CBO9780511807763

[35] O’Neill, P.V., De Angelis, D.L., Waide, J.B. and Allen, T.F.H. (1986) A Hierarchical Concept of Ecosystem. Princeton University Press, Princeton, 73-212. 